\title{
CRESCIMENTO VEGETATIVO E PRODUCÃO DE CAFEEIROS (Coffea arabica L.) RECEPADOS EM DUAS ÉPOCAS, CONDUZIDOS EM ESPAÇAMENTOS CRESCENTES ${ }^{1}$
}

\author{
Vegetative growth and yield of coffee plants (Coffea arabica L.) in two \\ different pruning times, conducted at different spacings
}

\author{
Sérgio Parreiras Pereira², Rubens José Guimarães ${ }^{3}$, Gabriel Ferreira Bartholo ${ }^{4}$, \\ Paulo Tácito Gontijo Guimarães ${ }^{5}$, José Donizeti Alves ${ }^{6}$
}

\begin{abstract}
RESUMO
O experimento foi instalado na Fazenda Experimental da Empresa de Pesquisa Agropecuária de Minas Gerais - EPAMIG em Machado, Sul de Minas Gerais, em 1992, com o objetivo de avaliar as conseqüências da redução dos espaçamentos entre as linhas e entre as plantas na linha de plantio sobre a produção e a fenologia do cafeeiro(Coffea arabica L.). O delineamento experimental foi o blocos casualizados - DBC, em um arranjo fatorial 4 x 3 com parcela subdividida, sendo quatro distâncias entre as linhas $(2,0 ; 2,5 ; 3,0$ e $3,5 \mathrm{~m}$ ) e três distâncias entre as plantas na linha de plantio $(0,5 ; 0,75 ; 1,0 \mathrm{~m})$, e duas épocas de poda (uma precoce feita logo após a colheita em de julho 2002 e a outra tardia em de janeiro de 2003), totalizando 24 tratamentos com três repetições. Em julho de 2002 e em janeiro de 2003 foi realizada a poda tipo "recepa", na qual foram conduzidas duas brotações por planta. Em agosto de 2004, avaliou-se o crescimento dos componentes vegetativos e a produção das parcelas. Os espaçamentos adotados não influenciaram o crescimento de nenhum dos componentes vegetativos das brotações no período avaliado. Todas as características vegetativas foram influenciadas positivamente pela adoção da poda precoce, assim como a produtividade da primeira colheita realizada após a poda, que foi também influenciada positivamente pela adoção de espaçamentos mais adensados. Os cafeeiros que foram submetidos à poda tardia não produziram, em julho de 2004, como aqueles podados precocemente.
\end{abstract}

Termos para indexação: Fenologia, recepa, manejo, adensamento, Coffea arabica.

\begin{abstract}
The experiment was established in the Empresa de Pesquisa Agropecuária de Minas Gerais - Epamig Experiment Station, located in the city of Machado, south of the Minas Gerais state, Brazil, in the year of 1992, with the objective of evaluating the consequences of the reduction on planting spaces among rows and among plants, upon beans yield and plant phenology (Coffea arabica $\mathrm{L}$.). The experimental design used was a $4 \times 3$ factorial with split plot at four distances between planting rows $(2,0 ; 2,5 ; 3,0$ e $3,5 \mathrm{~m}$ ) and three distances among plants in the row $(0,5 ; 0,75$ e $1,0 \mathrm{~m}$ ), and two different pruning times (one precociously conducted just after the harvest, on july 2002, and the other latter on january 2003), making a total 24 treatments arranged in randomized blocks with three replicates. In july 2002 and january 2003 a drastic pruning was clone and conducing two sprouts per plant. Vegetative growth and beans yield were evaluated in august 2004. Coffee plant spacing did not affected growth of any of the vegetative components of sprouting, during the evaluated period. All the vegetative characteristics were positively affected by the early pruning procedure, as well as the beans yield of the first harvest after pruning, which also showed to be positively influenced by the adoption of a narrower spacing plant. The coffee plants which were submitted to late prunning, had lancer bean yield in july 2004 as those precociously prunned.
\end{abstract}

Index terms: Phenology, prunning, management, spacing of planting, Coffea Arabica.

\section{(Recebido em 27 de janeiro de 2005 e aprovado em 7 de fevereiro de 2006)}

\section{INTRODUÇÃO}

Desde que o cafeeiro (Coffea arabica L.) foi introduzido no Brasil em 1727, foi conduzido nas mais diversas formas de manejo, solos, clima e declividade, sendo que os espaçamentos, nos seus vários arranjos, procuraram sempre uma produtividade máxima. Atualmente, parece haver uma tendência de redução dos espaçamentos do plantio na maioria das culturas, especialmente das lenhosas perenes. No caso do cafeeiro, as principais vantagens dos plantios adensados são o ganho em produtividade, com maior eficiência na utilização da

\footnotetext{
'Parte da dissertação apresentada à Universidade Federal de Lavras/UFLA, pelo primeiro autor, para obtenção do grau de Mestre em Agronomia na área de Fitotecnia.

Engenheiro Agrônomo, M.Sc., Pesquisador do Instituto Agronomico de Campinas/IAC - pereiracafes@yahoo.com.br

${ }^{3}$ Engenheiro Agrônomo, Dr., Professor do Departamento de Agricultura/DAG da Universidade Federal de Lavras/UFLA - Cx. P. 3037 - $37200-000$ Lavras, MG.

${ }^{4}$ Engenheiro Agrônomo, Dr., Gerente geral da EMBRAPA - Café, Empresa Brasileira de Pesquisa Agropecuária.

${ }^{5}$ Engenheiro Agrônomo, Dr., Pesquisador da Empresa de Pesquisa Agropecuária de Minas Gerais/EPAMIG.

${ }^{6}$ Engenheiro Agrônomo, Dr., Professor do Departamento de Biologia/DBI da Universidade Federal de Lavras/UFLA - Cx. P. 3037 - $37200-000$ Lavras, MG.
} 
radiação solar, da água e dos minerais e, possivelmente, pelo melhor controle das plantas invasoras e algumas pragas como o bicho-mineiro, Leucoptera coffeella, (Guérin -Menéville, 1842) (Lepidoptera:Lyonetiidae).

Uma lavoura é considerada eficiente quando é capaz de formar, ano após ano, um extenso e bem iluminado dossel, com alta taxa fotossintética, capaz de produzir muitos grãos e de mobilizar grandes quantidades de carboidratos para enchimento dos frutos (RENA et al., 1994). O adensamento provoca uma alteração no ambiente da lavoura ocasionando modificações nos padrões fisiológicos, morfológicos e produtivos dos mesmos. Reduções no espaçamento de plantio, tanto entre as linhas quanto entre as plantas na linha, refletem em maior altura do ramo ortotrópico primário (NACIF, 1997; PEREIRA \& CUNHA, 2004; RENA et al., 1994), causam morte mais intensa dos ramos plagiotrópicos no terço inferior dos cafeeiros (MATIELLO et al., 2002; PEREIRA \& CUNHA, 2004; THOMAZIELLO et al., 1998) e diminuem a área útil produtiva de cada planta, representada pelo diâmetro e o comprimento da copa (PEREIRA \& CUNHA, 2004). Com este alto grau de fechamento, tanto entre, quanto dentro das linhas de plantio, é constatada a necessidade da poda, como instrumento de rejuvenescimento e manutenção da produtividade da lavoura, incrementando a rentabilidade do cafeicultor.

As várias partes de uma planta crescem em diferentes ritmos e em diferentes épocas do ano, devido à interação de fatores genéticos, nutricionais, hormonais e ambientais, e o cafeeiro não constitui exceção. O cafeeiro tem grande capacidade de se adaptar a modificações de ambiente (dentre elas, alterações no espaçamento), mediante modificações morfológicas, bioquímicas e fisiológicas .

Existe controvérsias a respeito da melhor época de se efetuar a operação de poda em cafeeiros; se logo após a colheita ou se após o início do período chuvoso. Guimarães \& Mendes (1997) afirmam que a época mais apropriada para a poda em cafeeiros é aquela que segue após a colheita, em agosto ou setembro, mas, nos casos de lavouras depauperadas, recomendam que aguarde até novembro-dezembro, para que as plantas tenham tempo de recompor suas reservas de fotoassimilados, para então efetuar a poda. De acordo com Matiello et al. (2002), a indicada para a poda é o período compreendido entre o término da colheita e o início das chuvas, normalmente em agosto-setembro. As podas menos drásticas devem ser realizadas mais cedo para possibilitar o arejamento da planta e um maior pegamento da florada. Já as podas mais drásticas (recepas) devem ser retardadas, pois quando antecipadas dentro do período seco, podem aumentar a porcentagem de morte de raízes.

O presente trabalho teve como objetivo avaliar as conseqüências da redução de espaçamentos entre as linhas e entre as plantas na linha de plantio sobre a crescimento vegetativo e a produção dos cafeeiros após a poda tipo "recepa", bem como avaliar a melhor época do ano para proceder essa operação.

\section{MATERIAL E MÉTODOS}

O presente trabalho foi conduzido por 12 anos na Fazenda Experimental da Empresa de Pesquisa Agropecuária de Minas Gerais (EPAMIG), em Machado, sul de Minas Gerais, de janeiro de 1992 até agosto de 2004, quando foram feitas as últimas avaliações.

O solo do local do ensaio é classificado como Latossolo Vermelho distróférrico, em uma área de relevo de plano a suave ondulado, originalmente sob vegetação de cerrado. A altitude da sede do município é de $881 \mathrm{~m}$, a latitude de $21^{\circ} 40^{\prime} \mathrm{S}$, a longitude de $45^{\circ} 55^{\prime} \mathrm{W}$. A precipitação e a temperatura média anual são de $1670 \mathrm{~mm} \mathrm{e} 21^{\circ} \mathrm{C}$, respectivamente.

O delineamento experimental utilizado foi o blocos casualizados - DBC disposto em um fatorial 4 x 3 com parcela subdividida, sendo quatro distâncias entre as linhas $(2,0 ; 2,5 ; 3,0$ e $3,5 \mathrm{~m})$, três distâncias entre as plantas na linha de plantio $(0,5 ; 0,75 ; 1,0 \mathrm{~m})$, e duas épocas de poda (uma precoce feita logo após a colheita no mês de julho 2002 e a outra tardia no mês de janeiro de 2003), totalizando 24 tratamentos com três repetições.

As parcelas mediam $12 \mathrm{~m}$ de comprimento, possuindo três linhas de plantio com distância variável $(2,0 ; 2,5 ; 3,0$ e $3,5 \mathrm{~m})$ em função do tratamento aplicado. Entre as plantas na linha foi aplicado o segundo fator $(0,5$; $0,75 ; 1,0 \mathrm{~m})$, totalizando 24,16 e 12 plantas por parcela, respectivamente. Considerou-se como parcela útil a linha interna, pois essa sofreu influência tanto do adensamento entre as linhas quanto entre as plantas na linha.

As parcelas foram subdivididas em duas, sendo as subparcelas então, constituídas por duas épocas de poda, uma precoce e a outra tardia.

Em julho de 2002, realizou-se a recepa a $40 \mathrm{~cm}$ do solo nas subparcelas da primeira época de poda. Em janeiro de 2003, realizou-se a recepa das subparcelas referentes à segunda época. Quatro meses após as recepas, foi feita uma desbrota, deixando-se duas hastes por tronco, no sentido da linha de plantio. Outras três desbrotas foram efetuadas em toda a área experimental. 
As características fenológicas foram avaliadas em agosto de 2004, tomando-se o comprimento e o diâmetro dos brotos, o diâmetro da copa, e o número de ramos plagiotrópicos. As unidades experimentais constituídas pelas quatro plantas centrais da subparcela, medindo-se os dois brotos e considerando-se, portanto, a média de oito brotos.

O comprimento dos brotos foi medido com uma régua graduada da sua base até o ápice dos mesmos. A medida de diâmetro da saia foi obtida da forma anteriormente descrita. $\mathrm{O}$ diâmetro dos brotos foi medido a $3 \mathrm{~cm}$ da base dos mesmos com o auxílio de um paquímetro. $\mathrm{O}$ número de ramos plagiotrópicos primários foi obtido por meio de contagem direta.

Em agosto de 2004, avaliou-se a produtividade somente nas subparcelas recepadas no mês de julho de 2002, uma vez que aquelas que receberam a poda tardia não apresentaram produção por ocasião da colheita. Determinou-se o peso dos frutos, na forma de "café da roça", por unidade experimental e por planta. O chamado "café da roça" é o café colhido com diversos estádios de maturação misturados: verde, cereja, passa e seco. Do total, retirou-se uma amostra de $2 \mathrm{~kg}$, que foi seca até $11 \%$ de umidade, beneficiada e pesada, transformando-se os dados obtidos em sacas de café beneficiado por hectare e em gramas de café beneficiado por planta.

Toda a área após as podas, independente da época da recepa, recebeu tratos culturais, como de adubações de solo e foliar, além do controle de plantas daninhas.

\section{RESULTADOS E DISCUSSÃO}

A redução no espaçamento entre as linhas de plantio não influenciou o desenvolvimento vegetativo em nenhuma das variáveis avaliadas, independentemente da época da poda (Tabela 1).

Nenhum dos componentes vegetativos apresentaram alterações significativas em seus padrões de crescimento até julho de 2004, ocasião em que foram realizadas as avaliações. Entre as podas e as avaliações fenológicas, as brotações dos cafeeiros se encontravam ainda com porte reduzido e com diâmetro da copa inferior a $1,00 \mathrm{~m}$ e, portanto as plantas não se tocavam, em nenhum espaçamento estudado, de forma a favorecer o auto-sombreamento o que poderia afetar o crescimento das plantas. Felipe et al. (2003), em um ensaio em que se avaliou o crescimento de plantas recepadas em três diferentes espaçamentos de plantio, observaram que os mesmos não influenciaram a altura da planta, o diâmetro da base da copa e o diâmetro da base do broto, indicando que, independentemente do espaçamento utilizado, as plantas de café apresentaram os mesmos padrões de crescimento vegetativo. Rena et al. (2003) afirmaram que os efeitos da redução do espaçamento sobre os componentes vegetativos da planta acentuam-se com o passar do tempo e que esses são mais afetados pelo espaçamento entre as plantas do que pelo espaçamento entre as linhas de plantio.

O fato de não ter sido detectadas diferenças nos componentes vegetativos em função da redução de espaçamento entre as linhas deve-se ao fato de que as plantas foram avaliadas aos dois anos em relação à primeira época de poda e a um ano e meio em relação à segunda época de poda, épocas em que as plantas individualizadas, ainda não se tocavam. De acordo com Akunda (1979), os cafeeiros se adaptam às variações do ambiente devido às alterações de espaçamento, o que até a avaliação não havia sido necessário.

TABELA 1 - Comprimento e diâmetro do broto, diâmetro da saia e número de ramos plagiotrópicos de cafeeiros, submetidos a diferentes espaçamentos entre as linhas de plantio e a duas diferentes épocas de poda. Machado - MG, Julho de 2004.

\begin{tabular}{|c|c|c|c|c|c|c|c|c|}
\hline \multirow[t]{2}{*}{$\begin{array}{l}\text { Espaçamento entre } \\
\text { as linhas (m) }\end{array}$} & \multicolumn{2}{|c|}{$\begin{array}{l}\text { Comprimento do } \\
\text { broto }(m)\end{array}$} & \multicolumn{2}{|c|}{$\begin{array}{c}\text { Diâmetro do broto } \\
(\mathbf{m m})\end{array}$} & \multicolumn{2}{|c|}{$\begin{array}{l}\text { Diâmetro da copa } \\
\text { (m) }\end{array}$} & \multicolumn{2}{|c|}{ Número de ramos } \\
\hline & $\begin{array}{l}\text { Julho } \\
2002\end{array}$ & $\begin{array}{l}\text { Janeiro } \\
2003\end{array}$ & $\begin{array}{l}\text { Julho } \\
2002\end{array}$ & $\begin{array}{l}\text { Janeiro } \\
2003\end{array}$ & $\begin{array}{l}\text { Julho } \\
2002\end{array}$ & $\begin{array}{l}\text { Janeiro } \\
2003\end{array}$ & $\begin{array}{l}\text { Julho } \\
2002\end{array}$ & $\begin{array}{c}\text { Janeiro } \\
2003\end{array}$ \\
\hline 2,00 & $107,1 \mathrm{a}$ & $70,5 \mathrm{a}$ & $31,7 \mathrm{a}$ & $19,3 \mathrm{a}$ & $120,5 \mathrm{a}$ & $78,6 \mathrm{a}$ & $20,4 \mathrm{a}$ & $15,9 \mathrm{a}$ \\
\hline 2,50 & $103,2 \mathrm{a}$ & $63,4 \mathrm{a}$ & $29,4 \mathrm{a}$ & $19,7 \mathrm{a}$ & 114,6 a & $78,7 \mathrm{a}$ & $20,4 \mathrm{a}$ & $15,2 \mathrm{a}$ \\
\hline 3,00 & $106,5 \mathrm{a}$ & $68,7 \mathrm{a}$ & $30,4 \mathrm{a}$ & $20,3 \mathrm{a}$ & $117,3 \mathrm{a}$ & 82,8 a & $20,7 \mathrm{a}$ & $15,3 \mathrm{a}$ \\
\hline 3,50 & $100,4 \mathrm{a}$ & $66,5 \mathrm{a}$ & $29,6 \mathrm{a}$ & $20,4 \mathrm{a}$ & 114,6 a & $83,2 \mathrm{a}$ & $19,7 \mathrm{a}$ & $15,1 \mathrm{a}$ \\
\hline C.V. (\%) & \multicolumn{2}{|c|}{9,03} & \multicolumn{2}{|c|}{6,01} & \multicolumn{2}{|c|}{8,82} & \multicolumn{2}{|c|}{4,80} \\
\hline
\end{tabular}

As médias seguidas pela mesma letra na coluna não diferem significativamente entre si, pelo teste de Scott-Knott, a $5 \%$ de probabilidade. 
Em relação à influência dos espaçamentos entre as plantas na linha de plantio o comprimento do broto, o diâmetro das copas e o número de ramos plagiotrópicos de cafeeiros não foram afetados pelos espaçamentos nas diferentes épocas avaliadas (Tabela 2).

Somente o diâmetro do broto foi afetado, na primeira época de poda, pelo espaçamento entre as plantas apresentando como maior diâmetro aquele de 1,00 m entre as plantas, significativamente superior ao de 0,50 e $0,75 \mathrm{~m}$, esses iguais entre si. Nacif (1997), trabalhando com plantas não podadas, observou influência dos espaçamentos entre as plantas sobre a variável diâmetro dos brotos e diâmetro das copas somente a partir dos 31 meses de idade. Vale a pena ressaltar que, não existe na literatura nenhuma menção à correlação entre o diâmetro dos brotos e a produção dos cafeeiros, e dessa forma, essa variável não apresenta influência sobre a área produtiva das plantas.

Felipe et al. (2003) encontraram resultados semelhantes aos apresentados, já a partir de um ano após a recepa, quando os maiores espaçamentos entre as plantas apresentaram maiores diâmetros de brotos. Rena et al. (2003) citam que o diâmetro do caule de cafeeiros não podados foi uma característica que sofreu influência linear negativa no sentido dos menores espaçamentos. Possivelmente, tal diferença não tenha se pronunciado nas plantas podadas em janeiro por não ser a melhor época para essa prática. Augusto et al. (2001) observaram interações entre seis cultivares e os espaçamentos adotados, portanto, características como essas devem ser observadas na escolha do espaçamento. Os resultados apresentados demonstram que assim como para o espaçamento entre linhas, o espaçamento entre plantas não influenciou o crescimento dos componentes vegetativos dos cafeeiros podados em função da individualidade que cada planta se apresentava até a data da avaliação, mantendo o ambiente e a insolação iguais entre as plantas independentemente da distância adotada.

Todos os componentes vegetativos avaliados foram afetados pela época de poda. Os cafeeiros podados em julho de 2002 tiveram maior comprimento e diâmetro do broto, diâmetro da saia e número de ramos plagiotrópicos em relação àqueles podados em janeiro de 2003 (Tabela 3).

Cunha (1997), comparando diferentes épocas de recepa, concluiu que, entre os meses de agosto, novembro e janeiro dever-se-ia optar por podar os cafeeiros no mês de novembro, pelo fato de que a poda na estação chuvosa propiciaria melhores condições de recuperação da planta. Guimarães \& Mendes (1997) citam que a época mais apropriada para a poda em cafeeiros seria após a colheita, em agosto ou setembro. De acordo com Matiello et al. (2002), a época do ano indicada para a poda seria o período compreendido entre o término da colheita e o reinício das chuvas, normalmente em agosto-setembro. Livramento et al. (2001) afirmam que os efeitos da poda são mais positivos quando ela é realizada logo após a colheita e que estando o produtor impossibilitado de fazê-lo nessa época, seria recomendado que se fizessem todos os tratos culturais entre a colheita e a poda.

Os cafeeiros podados em julho de 2002 apresentaram, em agosto de 2004, produção significativa, ao contrário daqueles podados em janeiro de 2003, que, por ocasião da colheita não chegaram a produzir.

Os cafeeiros submetidos à poda tardia não produziram por não possuírem ainda, durante as fases fenológicas, principalmente durante a iniciação floral do ano de 2004, ramos maduros para que ocorressem a iniciação floral e as conseqüentes fases fenológicas da reprodução dos cafeeiros. Fato semelhante foi observado por Cunha (1997) em que os cafeeiros podados em agosto produziram 4,76 sacas por hectare e aqueles podados em janeiro produziram apenas 0,83 sacas por hectare, ou seja, $83 \%$ menos que os cafeeiros podados logo após a colheita. Dessa maneira, optou-se por proceder as análises relativas à produção dos cafeeiros somente para aqueles podados em de julho de 2002.

No café arábica as inflorescências são formadas nas axilas das folhas opostas dos ramos laterais (plagiotrópicos) crescidos na estação anterior, sendo que esses nós produzem flores apenas uma vez (DEAN, 1939, citado por RENA \& MAESTRI, 1984). Esse fato faz com que o crescimento de ramos seja uma das características a serem usadas para se fazer previsões de safra do ano seguinte, ou seja, quanto maior o crescimento dos ramos plagiotrópicos, maior será o potencial produtivo do ano seguinte, pela presença de maior número de nós e, conseqüentemente, maior número de inflorescências.

Portanto, o presente trabalho confirma que os cafeeiros devem ser podados, independente do espaçamento adotado, logo após o término da colheita, para que, após dois anos, os cafeeiros já apresentem capacidade vegetativa de produção.

A primeira produção após a intervenção da recepa foi influenciada pelos espaçamentos entre as linhas de plantio, tanto por planta, quanto por unidade de área. (Tabela 4). Os espaçamentos menores: 2,00; 2,50 e 3,00 m, significativamente iguais, tiveram produção individual por planta inferior ao de $3,50 \mathrm{~m}$, porém, apresentaram produção por hectare maior. Felipe et al. (2003) encontraram, em 
cafeeiros podados, menor produção individual em cafeeiros adensados e Nacif (1997), trabalhando com cafeeiros sem poda, obteve na primeira colheita, um acréscimo de $23 \%$ na produção por planta quando adotou o espaçamento de 3,00 m, em vez do 1,50 m entre as linhas de plantio, semelhante aos $32 \%$ obtidos no presente ensaio quando se comparou o espaçamento de $3,50 \mathrm{~m}$ com o de $2,00 \mathrm{~m}$. A menor produção por hectare deve-se ao fato de que, nesse espaçamento largo, se obtém sensível diminuição do número de plantas por hectare, o que de acordo com Guimarães et al. (1994), Mendes et al. (1994), Nacif (1997) e Rocha et al. (2000) é responsável pelo incremento produtivo por unidade de área.

As produções por planta e por hectare foram também influenciadas pelos espaçamentos entre as plantas na linha de plantio (Tabela 5).

TABELA 2 - Comprimento e diâmetro do broto, diâmetro da saia e número de ramos plagiotrópicos de cafeeiros submetidos a diferentes espaçamentos entre as plantas na linha de plantio e a duas diferentes épocas de poda. Machado - MG, Julho de 2004.

\begin{tabular}{|c|c|c|c|c|c|c|c|c|}
\hline \multirow[t]{2}{*}{$\begin{array}{l}\text { Espaçamento entre } \\
\text { as plantas }(\mathrm{m})\end{array}$} & \multicolumn{2}{|c|}{$\begin{array}{l}\text { Comprimento do } \\
\text { broto }(\mathrm{m})\end{array}$} & \multicolumn{2}{|c|}{$\begin{array}{l}\text { Diâmetro do broto } \\
(\mathrm{mm})\end{array}$} & \multicolumn{2}{|c|}{$\begin{array}{l}\text { Diâmetro da copa } \\
(\mathbf{m})\end{array}$} & \multicolumn{2}{|c|}{ Número de ramos } \\
\hline & $\begin{array}{l}\text { Julho } \\
2002\end{array}$ & $\begin{array}{l}\text { Janeiro } \\
2003\end{array}$ & $\begin{array}{l}\text { Julho } \\
2002\end{array}$ & $\begin{array}{l}\text { Janeiro } \\
2003\end{array}$ & $\begin{array}{l}\text { Julho } \\
2002\end{array}$ & $\begin{array}{l}\text { Janeiro } \\
2003\end{array}$ & $\begin{array}{l}\text { Julho } \\
2002\end{array}$ & $\begin{array}{c}\text { Janeiro } \\
2003\end{array}$ \\
\hline 0,50 & $108,1 \mathrm{a}$ & $63,5 \mathrm{a}$ & $29,1 \mathrm{~b}$ & $20,4 \mathrm{a}$ & $120,8 \mathrm{a}$ & $82,8 \mathrm{a}$ & $21,1 \mathrm{a}$ & $15,8 \mathrm{a}$ \\
\hline 0,75 & $103,8 \mathrm{a}$ & $65,1 \mathrm{a}$ & $29,7 \mathrm{~b}$ & $19,8 \mathrm{a}$ & $117,0 \mathrm{a}$ & $80.6 \mathrm{a}$ & $20,4 \mathrm{a}$ & $15,2 \mathrm{a}$ \\
\hline 1,00 & $101,0 \mathrm{a}$ & $73,2 \mathrm{a}$ & $32,0 \mathrm{a}$ & $19,6 \mathrm{a}$ & $112,4 \mathrm{a}$ & $79,8 \mathrm{a}$ & $19,5 \mathrm{a}$ & $15,1 \mathrm{a}$ \\
\hline C.V. (\%) & \multicolumn{2}{|c|}{9,03} & \multicolumn{2}{|c|}{6,01} & \multicolumn{2}{|c|}{8,82} & \multicolumn{2}{|c|}{4,80} \\
\hline
\end{tabular}

As médias seguidas pela mesma letra na coluna não diferem, significativamente entre sí pelo teste de Scott-Knott, a $5 \%$ de probabilidade.

TABELA 3 - Comprimento e diâmetro do broto, diâmetro da saia e número de ramos plagiotrópicos de cafeeiros, em julho de 2004, em função de duas épocas de poda. Machado - MG, 2004.

\begin{tabular}{ccccc}
\hline Época de poda & $\begin{array}{c}\text { Comprimento do } \\
\text { Broto }(\mathbf{m})\end{array}$ & $\begin{array}{c}\text { Diâmetro do Broto } \\
(\mathbf{m m})\end{array}$ & $\begin{array}{c}\text { Diâmetro da copa } \\
(\mathbf{m})\end{array}$ & Número de ramos \\
\hline Julho de 2002 & $104,3 \mathrm{a}$ & $30,3 \mathrm{a}$ & $116,7 \mathrm{a}$ & $20,3 \mathrm{a}$ \\
Janeiro de 2003 & $67,2 \mathrm{~b}$ & $19,9 \mathrm{~b}$ & $81,0 \mathrm{~b}$ & $15,4 \mathrm{~b}$ \\
\hline C.V. $(\%)$ & 9,03 & 6,01 & 8,82 & 4,80 \\
\hline
\end{tabular}

As médias seguidas pela mesma letra na coluna não diferem-se significativamente entre sí pelo teste de Scott-Knott a $5 \%$ de probabilidade.

TABELA 4 - Produção em gramas por planta e produtividade em sacas por hectare de café beneficiado, em função dos espaçamentos entre as linhas de plantio - cafeeiros podados em julho de 2002 e colheita em agosto de 2004. Machado - MG, Julho de 2004.

\begin{tabular}{ccc}
\hline Espaçamento entre as linhas de plantio $(\mathbf{m})$ & Produção (g/planta) & Produtividade (sc/ha) \\
\hline 2,00 & $244 \mathrm{~b}$ & $28 \mathrm{a}$ \\
2,50 & $279 \mathrm{~b}$ & $26 \mathrm{a}$ \\
3,00 & $301 \mathrm{~b}$ & $26 \mathrm{a}$ \\
3,50 & $360 \mathrm{a}$ & $20 \mathrm{~b}$ \\
\hline C.V. $(\%)$ & 13,67 & 14,85 \\
\hline
\end{tabular}

As médias seguidas pela mesma letra na coluna não diferem-se significativamente entre sí pelo teste de Scott-Knott a $5 \%$ de probabilidade. 
TABELA 5 - Produção em gramas por planta e produtividade em sacas por hectare de café beneficiado, em função dos espaçamentos entre as plantas na linha de plantio - cafeeiros podados em julho de 2002 e colheita em agosto de 2004. Machado - MG, Julho de 2004.

\begin{tabular}{ccc}
\hline $\begin{array}{c}\text { Espaçamento entre as plantas na } \\
\text { linha de plantio (m) }\end{array}$ & $\begin{array}{c}\text { Produção } \\
\text { (g/planta) }\end{array}$ & $\begin{array}{c}\text { Produtividade } \\
\text { (sc/ha) }\end{array}$ \\
\hline 0,50 & $211 \mathrm{~b}$ & $27 \mathrm{a}$ \\
0,75 & $325 \mathrm{a}$ & $26 \mathrm{a}$ \\
1,00 & $334 \mathrm{a}$ & $20 \mathrm{~b}$ \\
\hline C.V. $(\%)$ & 13,67 & 14,85 \\
\hline
\end{tabular}

As médias seguidas pela mesma letra na coluna não diferem significativamente entre si, pelo teste de Scott-Knott, a $5 \%$ de probabilidade.

Os espaçamentos de $0,75 \mathrm{~m}$ e $1,00 \mathrm{~m}$, considerados estatisticamente iguais, foram responsáveis pelas maiores produções individuais, quando comparados ao espaçamento de $0,50 \mathrm{~m}$.

Resultados apresentados por Nacif (1997) demostraram logo na primeira safra após o plantio, um acréscimo produtivo da ordem de $60,5 \%$ para o espaçamento de $1,50 \mathrm{~m}$, quando comparando com o de $0,50 \mathrm{~m}$ entre as plantas na linha.

Observou-se um acréscimo produtivo individual de $36,5 \%$ para o espaçamento de $1,00 \mathrm{~m}$, comparando-o com o de $0,50 \mathrm{~m}$ entre as plantas na linha. Os dados obtidos estão de acordo com as observações feitas por Camargo et al. (1983) que concluiram que o adensamento é responsável pela menor produção por planta, porém, com maior produtividade por hectare.

A maior produtividade por hectare foi também observada no presente trabalho, em que os espaçamentos de 0,50 e $0,75 \mathrm{~m}$, estatisticamente iguais, apresentaram produção superior ao de $1,00 \mathrm{~m}$ entre as plantas, mesmo tendo esse último apresentado a maior produção por planta. Felipe et al. (2003) observaram produtividade superior na primeira colheita após a poda em cafeeiros naqueles plantados a 0,60 m de distância entre si, quando comparados com aqueles plantados a 1,20 m. Nacif (1997) não encontrou diferença de produtividade entre os espaçamentos de $0,50 \mathrm{e}$ $1,00 \mathrm{~m}$ na primeira colheita, porém, observou um acréscimo de $14,1 \%$ entre os espaçamentos de 0,50 e $1,50 \mathrm{~m}$. Concluise que a vantagem do adensamento em relação à produtividade se pronuncia na primeira safra após a poda.

\section{CONCLUSÕES}

Os espaçamentos entre as linhas e entre as plantas na linha de plantio não influenciaram, no período avaliado, o crescimento dos componentes vegetativos das brotações de cafeeiros recepados. A melhor época de se podar o cafeeiro é logo após a colheita. A redução no espaçamento tanto entre as linhas quanto entre as plantas na linha de plantio mostrou ser uma prática capaz de aumentar a produtividade da lavoura cafeeira na primeira produção após a poda.

\section{REFERÊNCIAS BIBLIOGRÁFICAS}

AKUNDA, E. M. W.; IMBAMBA, S. K.; KUMAR, D. High density plantings of coffee: I. microclimatic and related changes. East African Agricultural and Forestry Journal, Nairobi, v. 45, n. 2, p. 130-132, Oct. 1979.

AUGUSTO, H. S.; MARTINEZ, H. E. P.; CRUZ, C. D.; PEREIRA, A. A. Crescimento vegetativo do cafeeiro em espaçamentos adensados e suas correlações com a produtividade. In: SIMPÓSIO DE PESQUISAS DOS CAFÉS DO BRASIL, 2., 2001, Brasília. Anais... Brasília, DF: CBP\&DCafé, 2001. p. 1688-1996.

CAMARGO, A. P.; ALMEIDA, S. R.; MATIELlO, J. B. Ensaio de espaçamentos progressivos de café em Varginha, MG. In: CONGRESSO BRASILEIRO DE PESQUISAS CAFEEIRAS, 10., 1983, Poços de Caldas. Anais... Rio de Janeiro: IBC/GERCA, 1983. p. 246-249.

CUNHA, R. L. Efeito da época, altura da poda e adulação foliar na recuperação da cafeeiros depauperados. 1997. 51 f. Dissertação (Mestrado em Fitotecnia) - Universidade Federal de Lavras, Lavras, 1997.

FELIPE, C. R. P.; OLIVEIRA, C. A.; CAMARANO, L. F. Crescimento e produtividade de plantas recepadas de café cultivadas em três espaçamentos de plantio. In: SIMPÓSIO DE PESQUISAS DOS CAFÉS DO BRASIL, 3., 2003, Brasília. Resumos... Brasília, DF: CBP\&D-Café, 2003. p. 284. 
GUIMARÃES, P. T. G.; NACIF, A. P.; BARTHOLO, G. F. Produtividade de cafeeiros adensados nas condições do cerrado de Patrocínio, MG. In: SIMPÓSIO INTERNACIONAL SOBRE CAFÉ ADENSADO, 1994, Londrina. Anais... Londrina: IAPAR, 1994. p. 302-303.

GUIMARÃES, R. J.; MENDES, A. N. G Manejo da lavoura cafeeira. Lavras: UFLA/FAEPE, 1997. 49 p.

LIVRAMENTO, D. E.; ALVES, J. D.; BARTHOLO, G. F.; GUIMARÃRES, P. T. G.; MAGALHÃES, M. M.; FRIES, D.

D.; PEREIRA, T. A. Efeito da pulverização com solução de sacarose nos níveis de carboidratos e produtividades de cafeeiros. In: SIMPÓSIO DE PESQUISA CAFEEIRA DO SUL DE MINAS GERAIS, 3., 2002, Lavras. Anais... Lavras: UFLA, 2001. v. 3, p. 107-111.

MATIELLO, J. B.; SANTINATO, R.; GARCIA, A. W. R.; ALMEIDA, S. R.; FERNANDES, D. R. Podas. In:

Cultura de café no Brasil: novo manual de recomendações. Rio de Janeiro: MAPA/PROCAFÉ, 2002. p. 256-274.

MENDES, A. N. G.; GUIMARÃES, P. T. G; MELLES, C. C. A.; BARTHOLO, G. F. Estudo do espaçamento entre e dentro de fileiras para as cultivares Catuaí e Mundo Novo. In: SIMPÓSIO INTERNACIONAL SOBRE CAFÉ ADENSADO, 1994, Londrina. Anais... Londrina: IAPAR, 1994. p. 300-301.

NACIF, A. P. de. Fenologia e produtividade do cafeeiro (Coffea arábica L.), cv Catuaí sob diferentes densidades de plantio e doses de fertilizantes, no cerrado de Patrocínio, MG. 1997. 124 f. Tese (Doutorado) - Universidade Federal de Viçosa, Viçosa, 1997.
PEREIRA, S. P.; CUNHA, R. L. Caracterização fenológica e reprodutiva de cafeeiros em diversos espancamentos, antes e após a poda. 2004. 105 p. Dissertação (Mestrado em Fitotecnia) - Universidade Federal de Lavras, Lavras, 2004.

RENA, A. B.; MAESTRI, M. Fisiologia do cafeeiro. In: RENA, A. B.; MALAVOLTA, E.; YAMADA, T. (Eds.). Cultura do cafeeiro: fatores que afetam a produtividade. Piracicaba: Potafós, 1984. p. 13-85.

RENA, A. B.; NACIF, A. P.; GUIMARÃES, P. T. G. Fenologia, produtividade análise econômica do cafeeiro em cultivos com diferentes densidades de plantio e doses de fertilizantes. In: ZAMBOLIM, L. (Ed.). Produção integrada de café. Viçosa: UFV, 2003. p. 133-196.

RENA, A. B.; NACIF, A. P.; GUIMARÃES, P. T. G.; PEREIRA, A. A. Fisiologia do cafeeiro em plantios adensados. In: SIMPÓSIO INTERNACIONAL SOBRE CAFÉ ADENSADO, 1., 1994, Londrina, PR. Anais... Londrina: IAPAR, 1994. p. 71-85.

ROCHA, A. C.; CEOTTO, O. L.; PREZOTTI, L. C. Diversos espaçamentos para o plantio de café Catuaí na região serrana do Espirito Santo. In: SIMPÓSIO DE PESQUISA DOS CAFÉS DO BRASIL, 1., 2000, Poços de Caldas. Resumos expandidos... Brasília, DF: CBP\&D-Café, 2000. p. 1001-1003.

THOMAZIELLO, E. A.; OLIVEIRA, E. G;TOLEDO FILHO, J.A.; COSTA, T. E. Cultura do café. Campinas: CATI, 1998. 57 p. (Boletim técnico, 193). 